\title{
SABERES DA AÇÃO PEDAGÓGICA DE PROFESSORES DE EDUCAÇÃO FÍSICA
}

José Angelo Gariglio

RESUMO: O presente artigo trata dos resultados de uma pesquisa que teve como objeto de investigação a análise dos saberes da ação pedagógica de professores de Educação Física (EF). A pesquisa foi realizada com três professores/as (dois homens e uma mulher) e contou com vários instrumentos de coleta de dados, como entrevistas, observação do trabalho cotidiano dos professores e análise documental. A investigação teve como referencial teórico-metodológico central os conceitos advindos dos estudos que tratam da epistemologia da prática profissional. Os resultados do estudo apontam que esses professores edificam saberes profissionais de tipo singular aos conhecimentos acadêmicos. O estudo mostra, ainda, que o processo de construção dos saberes da ação pedagógica revelou-se fortemente articulado à especificidade pedagógica da disciplina a qual os professores pertencem.

PALAVRAS-CHAVE: Formação de professores; Saberes da ação pedagógica; Educação Física.

\section{KNOWLEDGE OF EDUCATIONAL ACTION PHYSICAL EDUCATION TEACHERS}

ABSTRACT: This article discusses the results of a survey that had at investigating the analysis of pedagogical action knowledge of physical education teachers. The survey was conducted with three teachers (two men and a woman) and included various data collection tools, as interviews, daily work of the teacher observation and document analysis. The investigation was central theoretical and methodological framework the concepts arising from studies dealing with the epistemology of professional practice. The study results indicate that these teachers build unique type of professional knowledge to academic knowledge. The study also shows that the construction process of pedagogical action knowledge proved to be strongly articulated the pedagogical specificity of content which teachers belong.

KEYWORDS: Teacher education; Pedagogical action knowledge; Physical Education. 


\section{autêntica}

\section{INTRODUÇÃO}

O tema referente aos processos de constituição dos saberes da base profissional dos professores é alvo crescente de estudos no âmbito das ciências da educação. Esses estudos têm como uma de suas preocupações investigar as práticas de ensino dos docentes em seus diferentes e singulares locais de trabalho, identificando nelas a singularidade do conhecimento e da habilidade profissional que demarcariam a especificidade do ofício docente.

Essas pesquisas, em linhas gerais, nutrem-se de questões como: o que sabem os professores? Quais os saberes que estão na base da profissão docente? Quais os saberes necessários para ensinar? O que esses saberes têm de original? Há diferença entre eles e os conhecimentos provenientes da formação inicial, das ciências da educação, dos conhecimentos curriculares? Caso haja, em que ponto eles são diferentes? Como esses saberes são construídos? Qual a relação entre a edificação desses saberes e a experiência profissional? Trata-se de habitus, rotinas, posturas, intuição, dom, bom senso e/ou de conhecimentos de tipo sui generis e competências? Qual a relação entre os saberes profissionais e os saberes acadêmicos e disciplinares? (BORGES, 2002)

Essas são questões que orientaram a nossa investigação e constituem o pano de fundo no qual tem origem o nosso objeto de estudo. Ele se situa, portanto, no universo das pesquisas contemporâneas sobre o ensino, mais particularmente dos estudos que se interessam pelos saberes, pela formação e pelo trabalho docente.

Tendo como referência o foco investigativo desses estudos, a pesquisa por nós realizada' buscou investigar os processos de construção dos saberes da base profissional de professores de Educação Física (EF) mediante as ações pedagógicas laboradas por esses docentes em meio a práticas de ensino demarcadas pelo trabalho com um componente disciplinar específico: a Educação Física. Interessou-nos investigar em que medida a prática de ensino desse e nesse campo disciplinar tem relação com o processo de edificação dos saberes pedagógicos dos professores de EF.

Mesmo compartilhando da ideia de que os saberes profissionais desses professores não estão resumidos ao domínio dos conteúdos de ensino - ou seja, que a esses professores não basta dominar nem conhecer profundamente os saberes de referência de sua disciplina curricular para dar conta das múltiplas e contraditórias contingências do ambiente de ensino na escola, e que os conhecimentos disciplinares, proposicionais, constituem falsa representação dos saberes docentes e a respeito de sua prática, porque não dão conta dos sincretismos que envolvem a forma como conhecem, pensam e agem os professores em situações de ensino. Entendemos que seria significativo investigar de que forma os professores de EF desenvolvem sua cultura docente ante os processos de socialização profissional demarcados pelo ensino desse componente disciplinar.

Assim, duas questões se apresentaram como fundamentais na organização da nossa reflexão: a primeira é que cada disciplina escolar ostenta o seu princípio de inteligibilidade, seu paradigma, sua matriz disciplinar que organiza a totalidade dos conteúdos num conjunto coerente. O paradigma disciplinar é fundamental porque determina as tarefas que serão desenvolvidas com os alunos, os conhecimentos declarativos a ensinar e os conhecimentos procedimentais correspondentes (DEVALY, 1995; SHULMAN, 1986).

A segunda é que as disciplinas escolares são entidades culturais dotadas de características sui generis, que, longe de ser mero reflexo de disciplinas científicas e acadêmicas, se constituem de campos de ação

\footnotetext{
${ }^{1}$ Esta pesquisa trata dos resultados de minha tese de doutorado. Este estudo contou com o apoio financeiro da CAPES.
} 


\section{autêntica}

fortemente marcados pelas contingências de tempo e espaço escolar, pelas cláusulas explícitas dos contratos pedagógicos e didáticos, pelas estratégias de ensino voltadas aos alunos, pelas exigências dos colegas, pelas necessidades imediatas da vida institucional e pelos sistemas de avaliação e seleção. Nesse sentido, uma disciplina escolar apresenta-se como um conjunto de saberes, de competências, de posturas físicas e/ou intelectuais, de atitudes, de valores, de códigos e de práticas que trazem as marcas da forma escolar (PERRENOUD, 200 ; CHERVEL, 1990).

Nessa direção, pareceu-nos significativo produzir uma investigação que se debruçasse mais detidamente sobre as complexas relações entre a especificidade da matriz disciplinar da EF e o processo de edificação dos saberes da base profissional de professores de EF. Enfim, nosso objeto de estudo visou a compreender os modelos ou tipos de ação desenvolvidos pelos professores de EF em virtude de uma inserção profissional na escola, que, a priori, nos parecia detentora de um conjunto de particularidades. Estamos entendendo aqui como modelos de ação as representações elaboradas e veiculadas pelos professores de EF a respeito da natureza de sua prática, representações essas que servem para defini-la, estruturá-la e orientá-la em situações de ação (TARDIF; LESSARD; LAHAYE, 1991).

\section{O OFÍCIO DOCENTE: UM OFÍCIO DE SABERES?}

Os estudos sobre o saber docente ganham força no início dos anos 1980 e certo prestígio na década de 1990, principalmente nos Estados Unidos. Essa produção teórica cresce em importância, entre outros motivos, pela constatação da dificuldade da escola em lidar com as novas exigências socioculturais advindas da concorrência internacional, consequência da globalização dos mercados e da crise do papel social da escola, bem como da dificuldade dos sistemas nacionais de ensino em lidar com uma escola de massa.

A crise da escola é atribuída, entre outras causas, à fragilidade da profissão docente, especialmente à pouca importância dada à formação dos professores e à dificuldade destes em lidar com as novas e complexas exigências sociais, pedagógicas e culturais. Assim, o que se apresenta como um remédio para os males evidenciados pelos fatores precedentes é o discurso que defende a necessidade de profissionalizar o magistério (TARDIF, LESSARD; LAHAYE, 1991; GAUTHIER et al., 1998).

As pesquisas sobre os saberes docentes surgem como que ligadas à questão da profissionalização do ensino e aos esforços feitos pelos pesquisadores em definir a natureza dos conhecimentos profissionais que servem de base para o magistério. Essa base de conhecimentos para o ensino é definida por Shulman (1986) como a agregação codificada ou codificável de conhecimentos, habilidades, compreensão e tecnologia, de ética e disposição e de responsabilidade coletiva - assim como um meio para representá-la e comunicá-la.

Cabe ressaltar que as pesquisas sobre o saber docente foram (e ainda são) influenciadas pela produção teórica sobre o profissional reflexivo desenvolvida por Schön (2000). Com os conceitos desenvolvidos por ele sobre o conhecimento na ação, deu-se grande impulso nos estudos sobre os processos de pensamento adotados pelos profissionais do ensino. Esses conceitos operaram uma crítica profunda à racionalidade técnica, que tende a reduzir a leitura dos fatos a modelos teóricos desvinculados da realidade concreta. O professor, ao ser reconhecido como um profissional reflexivo, ou seja, produtor de estratégias inteligentes que orientam o seu fazer pedagógico, reconhece, em contrapartida, que o ato pedagógico encerra múltiplas dimensões, sendo, portanto, quase impossível medi-las, prevê-las e controlá-las totalmente segundo métodos científicos. Também, no contexto profissional, ao lidar com as dimensões afetivas, relacionais, organizacionais, existenciais e sociais, de forma concomitante ou isoladamente, o professor vê-se obrigado a desenvolver 


\section{autêntica}

mais do que uma racionalidade científica, ou seja, uma racionalidade prática. Por sua vez, o ato pedagógico, ao ser reconhecido na sua complexidade, incerteza, instabilidade, contextualidade e singularidade, exige do professor práticas reflexivas que buscam responder às múltiplas necessidades das situações de ensino.

O reconhecimento de que nos fenômenos práticos, entre eles o ato pedagógico, existe uma reflexão na ação, componente inteligente que orienta toda a atividade humana e se manifesta no saber-fazer, motivou a produção de pesquisas que pudessem identificar e verificar como e quais são os saberes produzidos pelos professores no contexto das práticas docentes no interior das salas de aula. Tal corrente de estudos tem sido denominada "epistemologia da prática profissional", e para ela o exercício profissional docente é tomado como uma experiência na qual se produz conhecimento de tipo singular. Para Tardif (2000, p. 11),

[...] os saberes profissionais são saberes trabalhados, lapidados e incorporados no processo de trabalho docente e que só têm sentido em relação às situações de trabalho concretas, em seus contextos singulares e que é nessas situações que são construídos, modelados e utilizados de maneira significativa pelos trabalhadores do ensino.

Estudos no campo da epistemologia da prática profissional objetivam investigar e compreender como os saberes profissionais são integrados concretamente nas tarefas dos professores e como e por que esses os incorporam, produzem, utilizam, aplicam, validam, transformam ou abandonam, em função dos limites, das contingências e dos recursos inerentes às atividades educativas. Esses conhecimentos, por serem engendrados na complexidade e na singularidade da prática profissional, apresentam-se como de tipo sui generis. Os professores seriam, com base na concepção teórico-metodológica da epistemologia da prática profissional, produtores não de conhecimentos do tipo científico ou meros aplicadores de saberes, mas sim de "saberes" de variada latitude.

A noção de saber aqui proclamada, diferentemente do conhecimento científico, encerra um sentido mais amplo, uma vez que engloba os conhecimentos, as competências, as habilidades (ou aptidões) e as atitudes, isto é, aquilo que muitas vezes é chamado de saber, saber-fazer e saber-ser (TARDIF, 2000).

Assim, o corpo docente, na impossibilidade de transpor linearmente para a sua prática docente os saberes das disciplinas, do currículo e da formação profissional, dada a singularidade e a particularidade do ato de ensinar, constrói intermediações e traduções que o leva a produzir outros saberes por meio dos quais pode compreender e dominar a sua prática. Esses saberes constituem os fundamentos da competência dos professores, julgando com base neles a sua formação anterior e a pertinência e validade das reformas introduzidas por políticas educacionais nos programas ou nos métodos, assim como na resolução de problemas e conflitos advindos do exercício profissional. Enfim, é graças aos saberes da experiência que os professores concebem os modelos de excelência profissional no interior de sua profissão (TARDIF; LESSARD, 1999; GAUTHIER, 1998).

Seria, portanto, preciso que as ciências da educação procurassem compreender mais de perto e, eventualmente, agir sobre um aspecto que durante muito tempo foi negligenciado pelas pesquisas em educação: a materialidade do trabalho docente na sala de aula.

Gauthier et al. (1998) buscam aprofundar essa discussão, valendo-se das pesquisas sobre o trabalho docente produzidas atualmente, argumentando que o saber necessário para ensinar não pode ser reduzido ao conhecimento do conteúdo da disciplina. Quem ensina sabe muito bem que, para ensinar, é preciso muito 


\section{autêntica}

mais do que simplesmente conhecer a matéria, mesmo reconhecendo que esse conhecimento seja fundamental. Nesse sentido, pensou-se erroneamente por muito tempo que as habilidades necessárias à docência podiam ser resumidas ao talento natural dos professores, ou seja, ao seu bom senso, à sua intuição, à sua experiência ou mesmo à sua cultura. Essas ideias preconcebidas prejudicavam o processo de profissionalização do ensino, impedindo o desabrochar de um saber desse ofício sobre si mesmo. É o que os autores denominam "ofício sem saberes". Isso porque esses saberes permaneceram por muito tempo confinados na sala de aula, resistindo a sua própria conceitualização, mal conseguindo expressar-se.

Simultaneamente, o ideal de criar uma pedagogia científica, de redigir um código do saber-ensinar, contribui para desprofissionalizar a atividade docente, visto que esse ideal de cientificidade demonstrou dificuldades em passar no teste na prática. Isso se deve ao fato de que esses códigos, construídos dentro dos moldes da racionalidade técnica, tinham a limitação de não levar suficientemente em conta a complexidade e as inúmeras dimensões concretas da situação pedagógica. Assim como as ideias preconcebidas de um ofício sem saberes bloqueavam a constituição de saber pedagógico, essa versão universitária, científica e reducionista dos saberes negava a complexidade do contexto de ensino, impedindo o surgimento de um saber profissional. É como se, fugindo de um mal, se caísse em outro. Ou seja, passamos de um ofício sem saberes a saberes sem ofício, saberes esses que podem ser pertinentes em si mesmos, mas que pouco são reexaminados à luz do contexto real e complexo da sala de aula (GAUTHIER et al., 1998).

Gauthier et al. (1998) reforçam essa tese ao afirmar que o ofício docente é feito de saberes, e que o desafio da profissionalização deve motivar-nos a investigar os saberes próprios do ensino, sendo necessária, para isso, a produção de estudos que consigam revelar o contexto complexo e real no qual os professores encontram-se mergulhados. Esses autores apontam a necessidade de conhecer o que eles denominam "saberes da ação pedagógica". O saber da ação pedagógica é o saber experiencial² dos professores a partir do momento em que se torna público e que é testado através de pesquisas realizadas em sala de aula. Assim, os julgamentos dos professores e os motivos que Ihes servem de apoio (jurisprudência particular) podem ser comparados, avaliados e pesados a fim de estabelecer regras de ação que serão conhecidas e aprendidas por outros professores. Isso porque, no campo da pedagogia, o saber do professor é em grande parte privado e não passa por nenhuma comprovação sistemática como em outras profissões. Contudo, justamente por ser particular, essa jurisprudência só raramente chega ao conhecimento público para ser testada. Além disso, embora presente em toda prática profissional, uma jurisprudência particular não tem nenhuma utilidade para a formação de professores e não leva a um maior reconhecimento do status profissional dos docentes. ${ }^{3}$

Os saberes da ação pedagógica legitimados pelas pesquisas são atualmente o tipo de saber menos desenvolvido no reservatório de saberes dos professores e também, paradoxalmente, o mais necessário à profissionalização do ensino. Não poderá haver profissionalização do ensino enquanto esse tipo de saber não for mais explicitado, visto que os saberes da ação pedagógica constituem um dos fundamentos da identidade profissional do professor. Para a profissionalização do ensino seria essencial identificar saberes da ação pedagógica válidos e levar os outros atores sociais a aceitar a pertinência desses saberes. A profissionalização do ensino tem, desse modo, não somente a dimensão epistemológica no que diz respeito à natureza dos saberes envolvidos, mas também uma dimensão política no que se refere ao êxito de um grupo social em fazer com a população aceite a exclusividade dos saberes e das práticas que ele detém (GAUTHIER et al.,1998).

\footnotetext{
${ }^{2}$ Gauthier et al. (1998) apontam que o que limita o saber experiencial é exatamente o fato de que ele é feito de pressupostos e de argumentos que não são verificados e legitimados por meio de pesquisas e/ou pela sua integração aos programas de formação docente.

3 Para os autores supracitados, esses saberes não chegam a influenciar a formação de novos professores porque normalmente se perdem quando os docentes deixam de exercer seu ofício.
} 


\section{autêntica}

Os resultados da pesquisa sobre o saber da ação pedagógica poderiam contribuir enormemente para o aperfeiçoamento da prática docente ao colocá-lo em evidência. O nosso estudo tem como objetivo central investigar, compreender e descrever alguns dos aspectos da jurisprudência particular e dos saberes da ação pedagógica de professores de Educação Física.

\section{METODOLOGIA \\ OS SUJEITOS E O LOCUS DA PESQUISA}

A escolha dos professores a serem pesquisados não se deu de forma aleatória. Os sujeitos da nossa pesquisa possuem características que estão intimamente ligadas ao nosso objeto de estudo e se adequam aos seguintes critérios: ter formação superior, ter mais de dez anos de experiência profissional na área da EF, ter mais de cinco anos de experiência profissional na instituição na qual eles trabalham, estar submetido ao regime contratual de dedicação exclusiva e pertencer ao quadro efetivo da escola, ou seja, possuir estabilidade no emprego. Seguem abaixo algumas das características particulares dos professores participantes da pesquisa:

- O professor Mauro, de 34 anos, além de ter curso de magistério em Educação Física, se graduou, há 12 anos, nesse mesmo curso pela Universidade Federal de Viçosa, com especialização em Educação Física escolar; sua experiência com o ensino dessa disciplina é de aproximadamente 16 anos, dentre os quais há mais de 7 anos atua como professor da ETEF-MG ${ }^{4}$ (Escola Técnica Federal de Minas Gerais). Atuou profissionalmente em escolas públicas estaduais de ensino fundamental na região de Ouro Preto (MG) e em uma Unidade Descentralizada do CEFET-MG.

- O professor Leandro, de 42 anos, é graduado em Educação Física pela Faculdade de Educação Física de Volta Redonda, com especialização em Ciência do Futebol; tem 22 anos de experiência com o ensino dessa disciplina e trabalha na ETEF-MG há mais de 12. Ministrou aulas de EF em escolas de ensino fundamental e médio no estado de Rondônia, além de ter tido experiência na Diretoria de Esportes e Lazer da Secretaria Municipal de Educação de Ariquemes, nesse mesmo estado.

- A professora Márcia, de 34 anos, há 12 anos se graduou em Educação Física e ainda possui especialização em Educação Física Escolar e um curso de mestrado em Educação pela Universidade Federal de Minas Gerais; conta com 13 anos de experiência profissional com o ensino dessa disciplina e trabalha na ETEF-MG há aproximadamente 10 anos. Militou profissionalmente como professora de EF em escolas públicas estaduais de ensino fundamental na região de Ouro Preto (MG). ${ }^{5}$

Como podemos notar, os professores participantes possuem significativa trajetória profissional, não somente no ensino da Educação Física, mas também no ensino dessa disciplina dentro da ETEF-MG. São, portanto, interlocutores qualificados, detentores de significativo conhecimento sobre a área, sobre a escola e seu métier profissional.

O locus de investigação é uma instituição escolar da Rede Federal de Educação Tecnológica, situada na cidade de Ouro Preto. Há que se salientar os porquês da opção pela realização do nosso estudo numa escola profissionalizante da Rede Federal de Educação Tecnológica. Tal escolha explica-se pelos seguintes motivos: por entendermos que essas instituições e seus professores ainda carecem de ser mais e melhor investigadas, valendo-se do seu cotidiano de trabalho na escola; por ser uma escola de ensino médio que,

\footnotetext{
${ }^{4}$ Essa denominação dada à instituição onde ocorreu a pesquisa é fictícia.

${ }^{5}$ Os nomes Mauro, Leandro e Márcia não correspondem aos nomes verdadeiros dos professores pesquisados. Essa denominação é também fictícia, pois visa garantir um mínimo de privacidade aos nossos sujeitos de pesquisa. 


\section{autêntica}

em função dessa especificidade, tem seu currículo organizado por campos disciplinares bem demarcados e a formação de seus professores marcada pela lógica disciplinar; por compreendermos que as condições de trabalho dos docentes dessas instituições estão mais próximas das dos professores que trabalham nos países de onde importamos as bibliografias sobre os saberes docentes e, por fim, de ordem pessoal, uma vez que o autor desta tese é professor de uma escola profissionalizante também da Rede Federal de Ensino.

No que tange à questão das melhores condições de trabalho dos professores pertencentes à Rede Federal de Educação Tecnológica, que dariam a esses docentes patamar de desenvolvimento profissional diferente dos demais professores de escola públicas no nosso país, destacam-se: melhores salários perante a remuneração dos professores das demais redes públicas de ensino; qualidade da estrutura física da escola; carreira profissional que possibilita a estabilidade no emprego, adicionais por tempo de serviço e incentivos à qualificação acadêmica; tempo e condições institucionais para a reflexão coletiva dentro da escola (direito à formação continuada); o fato de ser uma instituição dotada de autonomia administrativa, patrimonial, financeira, que possibilita aos docentes maior autonomia profissional; e a existência do contrato de trabalho de 40 horas com dedicação exclusiva. Esses professores, portanto, não trabalham em outra instituição, dedicando-se totalmente a uma única unidade escolar. Entre outras vantagens, essas características propiciam a diminuição do volume de transferências, demissões ou pedidos de exoneração, o que facilitaria o cumprimento de todo o ciclo profissional desses docentes na mesma instituição.

Tomamos essa questão como fundamental, visto que entendemos que as pesquisas recentes sobre as práticas dos saberes docentes, produzidas recentemente no nosso país, vêm utilizando a bibliografia internacional, sem que se façam mediações necessárias com o contexto educacional brasileiro. Diferentemente do que acontece em países como os EUA, o Canadá, a França e a Inglaterra, os professores no Brasil convivem com a seguinte situação: cotidiano de trabalho no qual é frequente intensa rotatividade entre escolas; precariedade no contrato de trabalho; baixíssimos salários; inexistência de espaços de reflexão coletiva dentro das escolas; dupla e tripla jornada de trabalho em duas ou três escolas num mesmo dia; falta de autonomia dos estabelecimentos de ensino, que são fortemente tutelados por políticas educacionais autoritárias, dentre outras características que inibem a produção de um contexto de trabalho para que os professores se tornem e atuem como profissionais reflexivos.

\section{SOBRE AS TÉCNICAS DE COLETA DE DADOS}

No intuito de realizar uma descrição e uma análise densa do trabalho dos professores, fez-se necessário a utilização de diversas técnicas de coleta de dados. No desenvolvimento da pesquisa, lançamos mão da observação do cotidiano de trabalho dos professores, da entrevista e da análise documental. Com tais estratégias, buscamos comparar discursos distintos, confrontar posições de diferentes sujeitos sobre o mesmo tema e verificar contradições entre práticas e discursos.

Partimos da compreensão de que a observação direta se apresenta como instrumento fundamental de análise dos significados que os professores atribuem à realidade que os cercam e às suas próprias ações. Tardif et al. (1999) ratificam a importância da observação nos estudos acerca dos saberes dos professores quando nos lembram que a relação entre o conhecimento sobre o trabalho e o trabalho não apresenta transparência perfeita e controle completo: o trabalho constitui sempre um momento de alteridade ante a consciência do professor. O professor possui saberes, regras, rotinas e recursos incorporados ao seu trabalho sem que tenha conhecimento explícito sobre a sua posse. Diante do exposto, esses autores defendem que uma teoria 


\section{autêntica}

consistente sobre os saberes dos professores não se pode repousar exclusivamente sobre os discursos deles. Faz-se necessário observá-los no momento do ato pedagógico.

Concordando com a procedência dessa orientação, conduzimos seis meses de observação do trabalho dos professores. No total, foram oito meses de pesquisa; em um determinado mês, não houve nenhuma atividade em função de férias escolares, além de outro mês ter sido destinado somente à realização das entrevistas.

Todas as observações foram registradas por meio de anotações em um diário de campo que era dividido em três partes: descrições dos momentos observados; conversas com os professores após a aula; observações e reflexões do pesquisador. Na primeira parte, anotava-se os acontecimentos ocorridos nas aulas. Já a segunda era destinada aos relatos dos professores sobre questões que nós fazíamos imediatamente após a aula. Essas questões diziam respeito a determinadas intervenções dos professores durante a aula que não ficavam muito claras e que achávamos importante que fossem esclarecidas. A terceira parte do diário de campo dizia respeito às (nossas) reflexões, à identificação de fatos e atitudes recorrentes, a indagações e perguntas norteadoras referentes aos fatos e a acontecimentos por nós relatados.

A entrevista apresentou-se como ferramenta metodológica fundamental para a nossa investigação. Além de ajudar a esclarecer e a enriquecer a análise dos dados coletados na observação direta e na análise documental, a entrevista, por si só, possibilita revelar a complexidade singular das ações e das reações dos sujeitos em contextos sociais. Por entendermos que numa entrevista se produz um ambiente no qual o pesquisador tem acesso a importantes informações da vida privada do pesquisado, decidimos fazer as entrevistas com todos os sujeitos da pesquisa ao final de nossa trajetória investigativa. Pudemos, com isso, aprofundar, ainda mais, o sentimento de confiança mútua, operando a entrevista quando o sentimento de estranheza ou constrangimento diante de nossa presença na escola já havia diminuído significativamente.

Ainda acerca dessa nossa opção metodológica, levamos em consideração o instigante debate estabelecido por Tardif e Lessard (1999) sobre a conceituação do que eles defendem como sendo o "saber". Para eles, saber qualquer coisa ou fazer qualquer coisa de forma racional é ser capaz de responder às questões "por que você fez isso?" e "por que você diz isso?" oferecendo razões, motivos e justificativas susceptíveis de servir de validação ao discurso ou à ação.

Nesse espírito, não basta fazer bem uma coisa, é preciso também que o ator saiba por que faz as coisas de certa maneira. Os autores levantam essa questão com o objetivo de evitar que as pesquisas sobre os saberes docentes continuem a ser vítimas do que eles chamam de excesso etnográfico, ou seja, uma ideia deque tudo é tomado como saber: ideologias, crenças, sentimentos, emoções, intuição, habitus e rotinas. E perguntam: "Se tudo é saber, para que então estudar o saber?". Para eles, os saberes docentes seriam definidos como todos os atos e discursos nos quais o prático é capaz de fornecer razões visando a motivá-los. Assim, o uso da entrevista mais ao final do percurso investigativo teve como objetivo recolher o maior número de informações possíveis sobre o trabalho dos professores, a fim de que eles pudessem, de maneira clara, explicar seus motivos e as intenções orientadoras de suas práticas docentes.

Além das entrevistas e da observação do cotidiano de trabalhos dos professores, o uso da análise documental nesta pesquisa objetivou ampliar e enriquecer, ainda mais, a descrição da cena social em questão. Acreditamos que o estudo de documentos escritos pode ajudar a qualificar a leitura dos jogos sociais impressos na experiência docente no interior da vida social dos EEs. Cellard (1997) ajuda-nos a compreender melhor a importância da utilização de documentos em estudos de cunho sociológico quando afirma que o 


\section{autêntica}

seu uso ajudaria a acrescentar a dimensão do tempo à compreensão do social. Graças aos documentos, pode-se efetuar um corte longitudinal que favorece a observação e a contextualização, os processos de maturação e evolução dos indivíduos, de grupos, de conceitos, de conhecimentos, de comportamentos, de mentalidades e de práticas. A análise documental pode, assim, diminuir muito o grau de influência exercido pela presença do pesquisador sobre o pesquisado e reduzir possíveis constrangimentos nas observações de acontecimentos e comportamentos a estudar, eliminando a possibilidade de reação negativa dos sujeitos pesquisados sobre a operação da coleta de dados.

Em nossa pesquisa, foram estudados dois tipos de documentos produzidos pelos professores de Educação Física analisados: as produções coletivas e as produções pessoais. No que diz respeito às produções coletivas, foram analisados o planejamento anual, os projetos de atividades extracurriculares e os projetos de eventos acadêmicos organizados pela coordenação de área. Em relação aos documentos pessoais produzidos pelos professores de EF, pudemos analisar planos de aula, textos, planejamento de ensino, diários pessoais, avaliações, projeto de disciplina eletiva, entre outros documentos privados.

Para a análise desses documentos, buscamos estabelecer um diálogo com seus próprios autores. Dessa forma, os professores ajudaram-nos a esclarecer os motivos e os interesses que possuíam no momento da concepção e escrita desses documentos, considerando tanto os privados quanto os coletivos.

\section{SABERES PROFISSIONAIS NECESSÁRIOS AO ENSINO}

No desenvolvimento do trabalho de pesquisa, questionamos os professores de EF sobre quais seriam os saberes necessários para ensinar, ou melhor, o que eles aprenderam de mais importante durante a trajetória profissional dentro da escola. Ao emitirem suas respostas, fomos surpreendidos com elementos da realidade que, inicialmente, nos pareceram sem muito sentido e de difícil decodificação e compreensão, quais sejam: saber-ver ou saber-observar; saber-ouvir.

Diante disso, emergiram as seguintes questões: de que forma esses saberes estariam vinculados aos papéis específicos destinados aos professores de EF na escola? Qual a validade prática desses saberes? De que forma esses saberes ajudariam os nossos depoentes no enfrentamento dos desafios postos pelo universo da prática de ensino?

Em nossas idas e vindas aos dados da pesquisa, sejam eles oriundos das entrevistas, sejam decorrentes de nosso diário de campo, sejam ainda do aporte teórico utilizado no trabalho, fomos aos poucos tentando interpretar em seus discursos e atos um quadro de inteligibilidade e de sentido que justificassem suas razões de agir. Para tentar esclarecer essas e outras questões, incentivamos os nossos informantes a fornecer maiores esclarecimentos sobre a natureza e a função desses saberes.

A professora Márcia, ao ser questionada sobre quais seriam os saberes utilizados para ensinar e o que ela desenvolveu no exercício da profissão docente na escola, dá o seguinte depoimento:

A observação. Observar cada aluno. Observar o comportamento, as mudanças de comportamento e em que contexto essas coisas aconteciam, principalmente nesse universo dos adolescentes, o que eles, esses personagens, vestem e o que está por trás desse personagem dos alunos. Nesse universo adolescente, isso é muito fértil. Saber-ver e saber-ouvir. Na hora de aplicar aquilo que você tem como possibilidade, como instrumento, como conhecimento seu, saber fazer uso desses saberes. Eu acho que buscar o momento propício para qualquer intervenção, para qualquer coisa, é um movimento que o professor tem de desenvolver (Professora Márcia). 


\section{autêntica}

No seu relato, ao dar esclarecimentos sobre a função e a natureza do saber-ver e saber-observar e do saber-ouvir, a professora parece tentar dizer-nos que a sensibilidade para observar e ouvir são habilidades necessárias para uma ação docente e que o foco central de sua intervenção se direciona mais fortemente aos processos de formação e educação geral dos estudantes.

Quando nos relata a importância de saber-observar, ela talvez queira informar que seria de sumo interesse seu o desenvolvimento de habilidades pedagógicas que a capacitassem para saber ver os alunos para além das aparências, isto é, desenvolver uma sensibilidade mais fina para compreender a subjetividade deles. Como ela mesma destacou em um relato anterior, saber-observar facilitaria ver os seus alunos de maneira mais ampla. Assim, saber-observar, saber-ver e saber-ouvir são competências profissionais necessárias à intervenção pedagógica que visa, por meio de uma leitura mais sensível e aprofundada do perfil emocional e comportamental dos alunos, a atuar mais radicalmente em relação ao processo de constituição dos comportamentos e das atitudes dos discentes.

Não podemos deixar de mencionar que o fato de a professora Márcia ter referido que saber-ver e saber-observar constituem um aprendizado fundamental para o seu exercício profissional parece estar relacionado com a capacidade de supervisionar ativamente a aula. Como vimos, os professores usam diversas formas de supervisionar as atividades de ensino propostas nas aulas. Os docentes utilizam-se de deslocamentos físicos, da presença corporal como forma de mobilização dos alunos, de gestos e de varreduras visuais. Essas práticas se constituem em habilidades pedagógicas importantes e significativas para o bom andamento do trabalho dos professores de Educação Física. Tal importância pode ser explicada em razão do contexto de ensino que se mostrou sui generis, seja pelas condições ambientais nas quais a prática do ensino dessa disciplina ocorre - com presença mais intensa do ruído e recorrência do trabalho em grupo -, seja em razão de um senso prático que reveste esse contexto de ensino no qual a habilidade discursiva se apresenta menos importante.

Para fazer com que esse tráfico de influência que atravessa a sala de aula da EF não interdite as ações de ensino-aprendizagem programadas pelos professores, estes desenvolvem ações de controle, regulação e persuasão dos estudantes de forma a manter um ambiente propício às situações de ensino-aprendizagem. Alguns estudos vêm mostrando que a prática da supervisão ativa se apresenta como elemento importante da profissionalização dos professores na educação básica. Isso porque ela se constitui numa estratégia informal de avaliação e de responsabilização empregada pelos professores, de forma a manter o equilíbrio ecológico favorável à aprendizagem e em atenção aos objetivos dos professores (GAUTHIER et al., 1998).

Os efeitos da supervisão ativa poderiam ajudar os professores da seguinte forma: manter a motivação; criar condições de maior segurança aos alunos; prevenir e colocar fim às perturbações; sincronizar as intervenções; formular as retroações pertinentes e produtivas; produzir estratégias significativas de implicação dos alunos nas tarefas (DESBIENS, 2003).

Nessa direção, podemos destacar que, quando a professora Márcia afirma que saber-observar ou saber-ver foram os saberes pedagógicos mais significativos apreendidos no exercício da profissão, ela pode estar se referindo à capacidade de ser eficaz na interpretação de eventos em curso na sala de aula, mas também à capacidade de intervir de maneira apropriada sobre o curso das ações. Dessa forma, a supervisão ativa aparece como estratégia fundamental no processo de condução do seu trabalho.

Ao observamos o trabalho dos professores de EF na sala de aula, foi possível detectar, dentre outros fatores, que parte significativa da divisão do tempo da aula era destinado "apenas" a supervisionar de maneira ativa o 


\section{autêntica}

trabalho dos alunos. Ou seja, eles ficam observando os acontecimentos, o comportamento e o envolvimento dos discentes nas atividades de ensino. Sua intervenção opera-se de maneira indireta, objetivando controlar e mobilizar os estudantes por meio do olhar atento, de expressões faciais de aprovação ou desaprovação, de gestos e sinais.

Ainda sobre a especificidade da ação docente em EF, pudemos constatar também que a capacidade de supervisionar ativamente as tarefas de ensino reporta à necessidade de criar condições adequadas para a segurança física dos alunos. As ações e as intervenções dos professores são mediadas, em muitos momentos, pelo cuidado com a manutenção da integridade corporal, de forma a diminuir, ao máximo, situações que porventura poderiam provocar acidentes e desgastes físicos desnecessários.

Mais adiante, quando indagada ainda sobre a relevância desses saberes para o seu trabalho, Márcia acaba nos revelando que eles são de fundamental importância para uma intervenção pedagógica diferenciada e qualificada do professor na escola. Para ela, essa capacidade de intervir seria medida pela habilidade de saber-ver e de modificar o comportamento dos alunos:

Eu acho que isso é fundamental num professor. O professor que entra e sai da sala de aula e não dá conta de que tipo de comportamento ele conseguiu interferir naquele dia, ou se não conseguiu, e do que ele tira daquele dia em relação ao grupo de alunos que ele pegou no começo da aula não tem consciência, na minha opinião, do que ele está fazendo ali na frente. Porque chegar ali e falar, falar, falar, eu sinceramente acho que não precisa ser professor para isso (Professora Márcia).

Evidencia-se nesse relato que, para essa professora, a habilidade de transmissão do conhecimento específico não seria fundamental para o reconhecimento das competências profissionais. A restrita transmissão do conteúdo ou a lógica transmissiva, que muitas vezes fundamenta o agir profissional no contexto do ensino médio organizando e definindo parâmetros do que seja um "bom" ou um "mau" professor, não se apresenta como determinante para a definição de princípios ordenadores de habilidades pedagógicas necessárias à sua intervenção pedagógica na escola. Isso porque seria preciso desenvolver habilidades pedagógicas que podem ficar restritas ao domínio do conhecimento disciplinar.

Mais do que isso, Marcia nos instiga a pensar que o trato com o conhecimento específico da EF não pode ser descolado da intervenção no processo de formação geral dos alunos. Ao lidar profissionalmente com o ensino da cultura corporal de movimento, seria possível ao professor desenvolver saberes profissionais de tipo sui generis. Por esse motivo, a prática de ensino da e na EF se apresentaria como um espaço de intervenção pedagógica no qual os seus professores, com relação a essa disciplina, são determinantes e determinados.

Além disso, ela nos revela que a habilidade discursiva não se apresenta como ferramenta profissional essencial para a sua intervenção pedagógica. Falar, falar, falar é fácil, o difícil seria ter sensibilidade para ver o subterrâneo existencial dos alunos, a sua subjetividade, observar e saber intervir na forma como eles conduzem suas atitudes, ter sensibilidade para perceber na fala deles seus sentimentos, seus desejos e as normas de sua conduta com os demais colegas. O relato da professora Márcia mostra-se diferente do que Monteiro (2001) expôs em sua tese acerca do trabalho docente de professores de História de uma escola pública de ensino médio do Rio de Janeiro. Ela revelou que, para os professores de História, a habilidade narrativa ou discursiva se apresenta como fundamental no desenvolvimento de sua prática docente. 


\section{autêntica}

Essa sensibilidade para interpretar a personalidade dos alunos foi também manifestada pela professora Márcia quando ela citou as razões pelas quais ela escolheu o curso de EF. Retomemos resumidamente o que ela nos disse quando indagada sobre como ser uma profissional da EF possibilitou-lhe atender parte de suas expectativas do que seria a sua atuação como uma profissional da Psicologia:

Por ser a Psicologia uma área de grande interesse, eu também tenho procuro leituras nessa área e busco coisas que me levem para mais próximo da área de que eu ainda gosto. Eu tentei pedir uma obtenção de novo título na UFMG, porque eu faria o curso de Psicologia. É um curso que eu tenho desejo de fazer. E acho que esse interesse interfere na minha prática, sim. Porque eu procuro, eu acho que até no meu jeito de ser, essa coisa nas pessoas, o conhecimento, tentar identificar certas coisas nas pessoas, observar. Acho que sou uma pessoa muito observadora, que estou muito atenta às mudanças de comportamento, e isso eu consigo trazer para as minhas aulas de Educação Física. Eu acho que a Educação Física é muito rica nessas possibilidades, a gente tem a proximidade com o outro, que talvez outras disciplinas não deem conta, essa possibilidade tão alargada quanto na EF. Eu acho que na Educação Física a gente é privilegiada por poder lidar com essa relação (Professora Márcia).

Podemos perceber nesse relato que a professora busca na Psicologia, ou no que ela entende serem as habilidades profissionais próprias de um psicólogo, conhecimentos necessários à sua intervenção pedagógica na EF. Realça entre esses saberes a sensibilidade para observar o perfil comportamental dos estudantes, para saber se relacionar com indivíduos ou grupos, entre outros. Mais do que isso, ela reconhece que a habilidade para observar seria mais necessária para os professores de EF graças a determinadas especificidades do contexto de ensino próprio a esse componente curricular.

Quando nos deparamos com os relatos do professor Leandro sobre os saberes que ele apreendeu e/ou desenvolveu no exercício de sua prática docente, notamos categorias semelhantes às mencionadas pela professora Márcia:

Ouvir. É, por mais "borracha" que quem quer que seja vá falar, eu ouço, porque ali dá para a gente pegar, tem sempre alguma coisa boa. Tem que saber ouvir mesmo. Com certeza. Saber ouvir, porque às vezes a gente tem mais a ouvir, ficar calado, saber o momento de interferir (Professor Leandro).

Assim como Márcia, Leandro mostra-nos que saber-ouvir é muito importante para o seu trabalho em EF. Saber-ouvir parece vir atrelado à busca e à sensibilidade para manter interação com os estudantes. Estar atento ao que os alunos dizem e conversam durante a aula pode ser fundamental para que os professores encontrem meios de acesso a eles, a fim de que possam organizar de forma objetiva a condução de determinada intervenção pedagógica.

Ainda no intuito de compreender a jurisprudência particular dos professores quando eles destacam a centralidade do saber-ver e do saber-ouvir no desenvolvimento do seu trabalho na sala de aula, faz-se necessário relacionar tal juízo ao contexto específico do ensino em EF. Isso porque, nas observações que realizamos das aulas ministradas pelos três docentes, foram raras as vezes que as tarefas individuais se fizeram presentes de forma predominante. No contexto da nossa pesquisa, mostrou-se hegemônica a presença de dois conteúdos de ensino: esportes coletivos e jogos, brinquedos e brincadeiras. ${ }^{6}$ Dentro desses dois blocos de conteúdo,

\footnotetext{
${ }^{6}$ A Educação Física é uma prática pedagógica que, no âmbito escolar, seleciona e tematiza determinados elementos da produção sociocultural. Ou seja, seus conteúdos de ensino são as atividades expressivas corporais, como jogo, esporte, dança, ginástica, luta, entre outras, formas que configurariam o que podemos chamar de cultura corporal de movimento (CASTELLANI FILHO et al., 2009).
} 


\section{autêntica}

fica evidente a opção dos professores por desenvolver atividades de caráter mais grupal. Questionamos os nossos depoentes sobre os porquês desse fato. Vejamos o que eles responderam:

Se a turma tem um problema de relacionamento, eu vou usar o que eu tenho para lidar com isso, porque é um espaço em que a Educação Física tem o privilégio de lidar com esse tipo de situação. Eu posso observar, por exemplo, dois alunos que tenham alguma limitação no seu relacionamento; eu vou criando estratégias, eu me posiciono de forma que me coloque para que esses alunos se enfrentem de alguma forma. Na aula de EF, eu acho que eu tenho uma possibilidade de articular isso de diversas formas, então quando eu proponho, por exemplo, um pegador, em que eles têm que se agrupar, eles não estão escolhendo com quem vão se agrupar, e sim com quem está mais perto, e isso eu entendo que proporciona a quebra dessas coisas, não é quebra de moralidade, porque nem é esse o meu objetivo, mas é tornar a convivência deles mais ampliada para o contato com o outro de maneira diferente, entender o outro em outra perspectiva. Então eu tento fazer de outra forma. E eu acho que a atividade em grupo oferece várias possibilidades de apreensão. (Professora Márcia).

Por acreditar na questão da relação. É justamente desse detalhe de relação, de construir junto, de cooperar, de que ninguém faz nada sozinho, que, por menor que seja a contribuição de um elemento para o coletivo, para o grupo, ela tem que ser ouvida, saber ouvir. Disso eu não abro mão (Professor Leandro).

[...] do estreitamento das relações deles mesmos, de conviver com o diferente, de conviver com ideia diferente, de respeitar essa ideia diferente, de querer ser compreendido - porque a gente sempre quer -, mas de compreender as ações e de respeitar essas ações, o trabalho em grupo dá muito essa possibilidade, que eu acho riquíssimo nessa parte (Professor Mauro).

Os professores, ao justificarem as razões pelas quais operam o seu trabalho predominantemente com atividades grupais, destacam que o objetivo central de sua intervenção pedagógica seria o de tentar melhorar as relações intersubjetivas dos alunos, de interferir na formação de suas atitudes e de seus valores, de solucionar problemas de relacionamento dentro da turma. Dessa forma, o trabalho em grupo apresenta-se como fundamental para as suas pretensões pedagógicas, ditas específicas. Saber-ensinar por meio da experiência coletiva parece ser um dos diferenciais de sua prática de ensino em relação aos demais professores e disciplinas da escola. Com ela o professor procura garantir aos alunos a possibilidade do contato, da conversa e do debate, da relação interpessoal, da construção coletiva do jogo. Esses momentos interativos ocupam lugar central no processo de aprendizagem, compondo a cena social adequada para que o conteúdo seja transmitido.

A hegemonia da presença do esporte e dos jogos e brincadeiras ratifica a percepção, por parte deles, de que o trabalho coletivo seria uma característica própria dessa disciplina. ${ }^{7}$ Shulman (1986), ao tratar do conceito de conhecimento pedagógico da matéria ensinada, mostra-nos que não há como desvincular o conteúdo da Pedagogia. Ele destaca que os conteúdos de ensino organizados, representados e adaptados aos diversos

7 Ao tratar da especificidade pedagógica da EF, Bracht (1997) vai argumentar que os saberes transmitidos pela escola provêm, na sua maioria, de disciplinas científicas ou, então, de forma mais geral, de saberes de caráter teórico-conceitual. $\mathrm{O}$ autor entende que, diferentemente do saber conceitual, o saber de que trata a EF encerra uma ambiguidade ou duplo caráter: a) ser um saber que se traduz num saber-fazer, num realizar "corporal" pedagógico; b) ser um saber sobre esse realizar corporal. Betti (1994) amplia essa caracterização, apontando que a ação pedagógica a que se propõe a EF estará sempre impregnada da corporeidade do sentir e do relacionar -se. 


\section{autêntica}

interesses e habilidades dos aprendizes e, ainda, apresentados para a instrução, acabam por produzir um conhecimento que está para além da matéria em si. Ele se transformaria no conteúdo da matéria para ensinar. A participação nas lições em classe implicaria na integração de conhecimentos acadêmicos e de conhecimento social e interacional. A compreensão sozinha não é suficiente. A utilidade de tal conhecimento está no seu valor para julgamento e ação. A compreensão, argumenta o autor, estaria ligada ao julgamento e à ação ao uso apropriado dessa compreensão na tomada de sábias decisões pedagógicas.

Nessa linha, os conteúdos de ensino da EF contribuem significativamente para estruturar não somente as atividades a serem desenvolvidas com os alunos e, por consequência, as habilidades profissionais destinadas ao ensino. O conteúdo de ensino, portanto, não pode ser visto apenas como um mero objeto de transmissão, mas um substrato no qual os professores constroem seu repertório profissional (DURAND, 1996).

A efetivação dessa estratégia de ensino parece demandar, por parte dos nossos sujeitos de pesquisa, uma série de procedimentos de intervenção pedagógica para que eles consigam manter a mobilização e o envolvimento dos alunos nas tarefas propostas. Entre elas, podemos citar: a prática do deslocamento constante entre os grupos e os alunos, o engajamento do corpo com a utilização variada de gestos e expressões como forma de controle e comunicação com os discentes, a busca de mobilização e engajamento nas atividades pela força da menor distância física entre professores e alunos, a varredura visual e o controle pelo olhar e o encadeamento das ações.

O fato é que organizar as tarefas pedagógicas predominantemente na formatação grupal não se revelou uma dificuldade para os professores. Eles apresentaram enorme desenvoltura no trato desse tipo de atividade. Tais habilidades pedagógicas tornam-se ainda mais prementes porque, ao lado da predominância do trabalho em grupo, verifica-se que o ambiente no qual as aulas de EF ocorrem possui as seguintes características: tem delimitação física de maior amplitude, é ao ar livre (o que impõe a presença mais intensa do sol, do frio, do calor e do vento) e não é composto por móveis que impeçam o movimento corporal dos estudantes e professores (mesas, cadeiras e armários). Sendo assim, o uso restrito da linguagem oral não seria suficiente para manter a organização e a motivação da aula. Isso porque há uma maior intensidade das interações (permitidas) entre alunos, e com elas múltiplas formas de comunicação: gestos, conversas, gritos e expressões corporais.

Parece-nos que, ao elencar a capacidade de saber-ouvir como habilidade importante para a sua atuação profissional, os professores chamam a atenção para o fato de que, coma presença maior de ruídos, de formas diversas de interação e de disposição corporal de professores e alunos na sala de aula da EF, há de se aguçar a disposição para a escuta. Tal disposição, além de ajudar na objetivação da sua conduta, promoveria interação entre alunos e professores. E essa maior proximidade ajudaria na produção de um ambiente de ensino mais caloroso e, consequentemente, facilitaria a condução de uma prática pedagógica que pudesse intervir de maneira qualificada na educação geral dos estudantes.

A importância de saber-ver e saber-ouvir parece ter relação com a capacidade de decodificar os sentidos e significados provenientes das situações de ensino. Dada a recorrência e centralidade das atividades grupais, os professores precisariam saber traduzir, por meio de varreduras visuais, os acontecimentos vividos, o conteúdo das interações provocadas pelas tarefas em grupo; interpretar os conteúdos interativos produzidos como resultado do trabalho coletivo; intervir rapidamente diante da manifestação de comportamentos não muito apropriados de determinados alunos; e saber impor um ritmo ao ensino no qual o nível de motivação do grupo se mantenha favorável ao bom andamento da aula. 


\section{autêntica}

Parece-nos que o saber-ouvir vem vinculado ao saber-observar. Isso porque, para o bom andamento das aulas, é preciso ser capaz de recolher informações, compará-las e conservá-las. Saber-observar pode ser o mesmo que saber-interpretar. Algumas pesquisas têm nos mostrado que saber interpretar a sala de aula, 0 movimento dos alunos, suas reações, suas motivações, ou seja, o comportamento do sistema de classe, está no coração da competência profissional dos professores (DESBIENS, 2003; GAUTHIER et al., 2003.

Tardif e Lessard (1999) ratificam a importância da capacidade interpretativa dos docentes como habilidade fundamental para sua intervenção pedagógica quando observam que os professores são intérpretes do que se passa na sala de aula. Eles devem constantemente "ler e interpretar" a classe, o movimento dos alunos, suas atitudes, bem como seus progressos. Sobre esse olhar, grande parte do que se pode chamar de Pedagogia está relacionada à capacidade de interpretação dos professores. Nessa medida, os docentes podem ser definidos como leitores de situações.

Vejamos o que o professor Leandro nos expõe quando relata o que ele tenta observar durante o andamento de suas aulas:

\footnotetext{
Olha, eu procuro observar de maneira bem ampla tudo o que está ocorrendo. Então eu tento observar todas as situações possíveis, diretamente ligadas à aula ou não. E dali também pode surgir um grande momento para uma discussão. Por exemplo, questões internas da escola, questões afetivas do aluno, problemas. Relações entre eles, problema das "panelas" que existem (Professor Leandro).
}

De maneira detalhada, esse professor explica que uma de suas preocupações é observar como os alunos se comportam e se organizam coletivamente, os seus problemas afetivos e as "panelas" formadas entre eles. A observação torna-se fundamental na medida em que o que é captado dessa diversidade de relações humanas é tomado como objeto de sua intervenção docente. Diferentemente dos demais professores da escola, o conteúdo relacional produzido pelos alunos parece tornar-se objeto a ser trabalhado nas aulas. Esses conteúdos tomam dimensão diferenciada, uma vez que não se apresentam apenas como problemas e obstáculos que dificultam a aprendizagem dos conteúdos e tampouco são problemas a serem solucionados pelo setor de orientação pedagógica da escola. Eles são parte essencial das preocupações pedagógicas desses professores de EF, que mostram grande interesse em tentar ver os alunos para além de sua dimensão epistêmica. 


\section{autêntica}

\section{CONSIDERAÇÕES FINAIS}

Ao finalizarmos nosso trabalho tentaremos, nesta última parte do texto, revisitar os achados mais significativos do estudo no intuito de apontar, de forma sintética, as contribuições deste para o avanço do processo de compreensão dos conteúdos e das características dos saberes da ação pedagógica de professores de EF.

Ao analisarmos as propriedades internas dos saberes dos professores de EF pesquisados, foi possível confirmar, de forma inicial, o que os docentes da educação básica vêm dizendo, em outras pesquisas, acerca do perfil de seus saberes profissionais. Apesar de reconhecerem a importância de se compreender e dominar os conteúdos disciplinares, eles consideram que apenas esse conhecimento não é suficiente para dar conta da difícil tarefa de ensinar. No esforço de tornar os conhecimentos disciplinares acessíveis aos seus alunos e compreensíveis aos demais atores escolares, tais docentes edificam outros saberes pedagógicos que se mostraram centrais ao reconhecimento - pessoal e público - como profissionais da educação dotados de conhecimentos de variada latitude.

As ricas e originais simbioses que amalgamavam os conteúdos de ensino e a Pedagogia, organizados e atualizados de forma a atender aos diversos interesses e necessidades dos aprendizes, da instituição e dos próprios docentes, não podem ser descoladas do objeto de ensino da EF (a cultura corporal de movimento). Os saberes pedagógicos modelados pelos nossos sujeitos de pesquisa trazem consigo as marcas de um contexto de trabalho situado. Ficou evidenciado nas práticas dos professores que é quase impossível separar o conteúdo de ensino da pedagogia empregada ou o que é sabido de como ensiná-lo. Ou seja, conteúdo e Pedagogia revelaram ser partes de um corpo indistinto de compreensão (SHULMAN, 1986).

Esse contexto singular de ensino e as atribuições pedagógicas desse componente curricular, no interior da escola pesquisada, configuraram-se com as seguintes características:

- as modalidades de ordem e disciplina presentes nas práticas pedagógicas da EF mostraram-se diferenciadas das demais disciplinas escolares. Apesar de as aulas, quase sempre, ocorrerem com a presença de ruídos (risos, gritos, conversas), com intensa movimentação dos alunos e com a ocupação mais livre dos espaços, isso não era visto como problema ao bom andamento das aulas de EF, e sim como elemento constitutivo. O silêncio muitas vezes era tomado pelos professores de EF com um incômodo ou como um sinal negativo, que servia de parâmetro ao professor se a aula estava sendo boa ou ruim;

- a singularidade das condições ambientais da sala de aula da EF, seja por ela ser ao ar livre, seja pela configuração de espaços e limites físicos mais amplificados em relação à sala de aula tradicional, seja pela intensidade das intempéries do tempo, seja ainda pela inexistência de um mobiliário escolar tradicional (mesas, cadeiras, armários);

- o tipo de interação estabelecida entre os alunos e também entre alunos e professores mostrou-se afetivamente intenso, fato motivado tanto pela especificidade dos conteúdos da EF (esporte e jogos/recreação), que "impunham" a recorrência do trabalho coletivo e a exigência constante de comunicação entre os grupos e nos grupos, quanto pela inexistência de obstáculos físicos (palanque, mesa, cadeira), o que facilita o acesso e o contato com o outro;

- o cuidado e a atenção com a segurança e com a integridade física dos alunos, evidenciando-se, muitas vezes, como um elementos didático organizador das atividades pedagógicas;

- a forma de avaliação diferenciada do modelo tradicional de aplicação de provas, ou seja, por meio da conceituação por notas; 


\section{autêntica}

- a maneira como a escola enxerga o ensino da EF, isto é, como tempo/espaço educativo mais propício ao desenvolvimento da formação humana dos alunos (valores, comportamentos, atitudes), e não como disciplina dotada de saberes importantes para sua formação.

Ante esse contexto de ensino situado e singular, alguns saberes docentes emergiram como fundamentais ao desempenho pedagógico e ao seu reconhecimento profissional na escola dos professores de EF analisados. São saberes/fazeres que expressam os contornos do que denominamos cultura docente/pedagógica particular dos professores de EF. Elas se configuram como práticas de significação, que dizem respeito à forma como esses docentes compreendem o seu papel na escola, à própria instituição escolar e, nela, ao ensino da EF. São práticas e discursos que esses profissionais elaboram e professam e que estruturam formas próprias de inteligibilidade do mundo social e de produção de sentidos acerca da sua ação profissional na ETEF-MG, quais sejam:

- saber-observar, ouvir e interpretar o movimento corporal e os ruídos da sala de aula;

- desenvolver técnicas de supervisão ativa capazes de mobilizar os alunos nas atividades, o que é importante para se ter um ambiente de ensino mais seguro e para o controle das ações pedagógicas numa sala de aula dotada de condições ambientais sui generis;

- saber utilizar técnicas corporais como mecanismos de interação e comunicação com os alunos;

- desenvolver e utilizar estratégias de persuasão dos alunos, necessárias ao ensino de uma disciplina na qual as relações de poder entre alunos e professores revelaram-se menos verticalizadas;

- ter habilidade para usar espaços e objetos como instrumentos didáticos;

- saber-ensinar mediante a centralidade e a intensidade da presença do trabalho coletivo.

Nessas categorizações expressa-se o caráter multifacetado do trabalho docente na escola. São práticas profissionais que envolvem, ao mesmo tempo, dinâmicas espaciais, temporais, físicas, afetivas, sociais, institucionais e políticas. São os aspectos ergonômicos da ação docente que abarcam o sujeito, a atividade e o contexto como um todo (TARDIF, 2000). Nessa ordem, os saberes docentes dos professores de EF pesquisados são reveladores de conhecimentos que se desenvolvem condicionados por um determinado contexto de trabalho.

Na observação das aulas e do trabalho dos docentes na sua organização, revelou-se ser fundamental possuir habilidades pedagógicas capazes não de dar conta da centralidade das dimensões de sociabilidade, mas de transformar os saberes advindos dessa experiência cultural em saberes escolares ricos em conteúdos formativos. Saber ensinar num contexto intenso, que respeita a situações afetivas e relacionais, surge como fundamental para a constituição de um repertório de habilidades pedagógicas singulares, definidoras, para a escola e para os próprios docentes, da sua própria capacidade de ensinar.

Os conteúdos de ensino da EF parecem ter a capacidade de projetar e ligar essa disciplina e os seus professores na direção de proposições e problemas mais diretamente relacionados ao mundo cotidiano da escola, à sua cultura ou à uma escola que existe dentro de outra escola. Essa "outra escola" é entendida não como instituição que apenas transmite conhecimentos disciplinares, mas como meio de vida social. Sobre esse ponto, Perrenoud (2000) lembra que a noção de práticas sociais de referência (práticas profissionais, práticas de comunicação e de sociabilidade) permitiria às disciplinas, como a EF, a educação artística e a educação das línguas, denominar que aquilo a que elas se referem não é redutível aos savoir savants. Para o referido 


\section{autêntica}

autor, todas as disciplinas podem contribuir para a formação geral dos estudantes, mas algumas são orientadas explicitamente para esse objetivo.

Entre alguns exemplos dessa relação, parece-nos importante colocar em relevo o déficit de legitimidade acadêmica da EF no currículo escolar. Na pesquisa esse dado aparece como gerador de certezas particulares acerca da capacidade de ensinar identificadas pelos próprios docentes e pela instituição. Como resultado desse lugar ocupado pela EF no currículo, os professores de EF veem-se envoltos a contingências institucionais que os informam cotidianamente que a sua função pedagógica precípua seria aquela de interferir mais diretamente no processo de socialização dos alunos. O território de intervenção desses docentes estaria mais vinculado à ação de educar do que à de instruir.

Sobre esse ponto, Perrenoud (2000) lembra que a todas as disciplinas podem contribuir para a formação geral dos estudantes, mas algumas são orientadas explicitamente para esse objetivo. Essa marca da constituição da EF mostrou ter reflexos claros no perfil das práticas pedagógicas desenvolvidas pelos docentes pesquisados, bem como na forma que eles percebem e hierarquizam os conteúdos de seus saberes profissionais.

Dessa forma, as habilidades pedagógicas demonstradas pelos nossos professores e postas em prática no enfrentamento dos desafios de seu trabalho não podem ser desvinculadas do conhecimento que eles têm da disciplina que ensinam na escola. Seus saberes pedagógicos têm íntima relação com tudo o que envolve esse contexto de ensino situado. Esses saberes são trabalhados na relação pedagógica que os professores estabelecem com e nesse conteúdo de ensino, o que possibilita a produção de ações didáticas singulares, marcadas pelo caráter situado do ensino e aprendizagem em EF. São saberes que se edificam em meio a esse contexto de ensino, mas que não se restringem aos conhecimentos disciplinares.

Sustentados pelos dados deste trabalho, podemos afirmar que ensinar Educação Física e Matemática, por exemplo, não é fazer a mesma coisa, ou melhor, não é objeto de igual consideração. As pesquisas sobre os saberes docentes precisam desfazer certa noção de equidade no campo da profissionalidade docente. Este, por sua vez, comporta uma dimensão social fundamental e se insere em relações sociais marcadas pela negociação com um tipo de trabalho específico, com seus conteúdos, com suas exigências próprias, com suas finalidades situadas e com suas estratégias de controle e autonomia (TARDIF; LESSARD, 1999).

Não existe uma cultura docente comum ao conjunto dos professores, mas sim culturas profissionais produzidas por eles no processo de interação cotidiana com o seu trabalho, processo esse estruturado por diversas condições e contratos sistemáticos - ordens escolares, setores de ensino, campos de ensino, estabelecimentos de ensino e ambientes socioeconômicos da região -, nos quais exercem sua profissão. Há, portanto, que se fazer revelar as culturas docentes dos profissionais dos diversos campos disciplinares, daqueles que militam com disciplinas profissionalizantes, dos que trabalham com os portadores de necessidades especiais, dos que atuam na universidade, dos educadores de jovens e adultos, entre outros profissionais que compõem o vasto espectro da educação escolar.

Tomando por base os saberes profissionais que os nossos depoentes destacaram como aqueles que são significativos ao exercício da docência em EF no meio escolar, cabe questionar: pode a universidade ensinar aos futuros professores esses saberes? Como trabalhar com os novos docentes a habilidade de saber interpretar os acontecimentos ocorridos na sala de aula e as técnicas de supervisão ativa? Como trabalhar as habilidades de agir e pensar ao nível do estabelecimento de ensino, de saber seduzir individualmente e coletivamente o alunado, de construir rotinas e esquemas de ação que permitam uma ação profissional 


\section{autêntica}

mais eficaz, de saber utilizar os espaços e os objetos como recursos didáticos, de mobilizar e utilizar vários desses saberes ao mesmo tempo, tendo em vista a solução de dilemas pedagógicos que envolvem realidades afetivas, morais, temporais, espaciais e institucionais? Ou esses são saberes apreendidos, apenas, no efetivo exercício da profissão?

Tais constatações apontam para a necessidade de fazer com que esses saberes, na plenitude da sua complexidade, sejam incorporados aos currículos de graduação de novos licenciados. Os saberes da prática profissional, elaborados pelos professores experientes ao seu exercício profissional, devem tornar-se objetos de pesquisa e análise por parte dos professores formadores e de seus alunos ainda nesse ambiente de formação. Mais do que isso, esses saberes devem tornar-se uma referência importante na organização dos currículos dos cursos de licenciatura e na definição de linhas e questões de pesquisa.

Quando se apregoa que os professores são sujeitos do conhecimento e que os saberes por eles construídos deveriam transitar pelo meio acadêmico com a importância que merecem, está se tentando afirmar que a produção dos saberes sobre o ensino não pode ser mais privilégio exclusivo dos pesquisadores, os quais devem reconhecer que os professores também possuem saberes diferentes dos conhecimentos universitários, e que obedecem a outros condicionantes práticos e a outras lógicas de ação (TARDIF, 2000).

Concluímos afirmando a necessidade de avançarmos ainda mais em pesquisas que tenham como objetivo dar visibilidade à pluralidade dos conhecimentos próprios da diversidade de culturas profissionais que coexistem no sistema educativo. Os professores de Educação Física participantes da pesquisa demonstraram possuir saberes docentes que trazem as marcas do seu trabalho. Em seu "quintal", buscam dar sentido ao seu agir profissional, valendo-se de um lugar muito bem situado dentro da escola. Enfim, cabe aos docentes da educação básica, à escola e à universidade o papel de colocar em evidência a pertinência e a singularidade dos saberes da ação pedagógica, tirando-os do anonimato, como uma forma de ação política que tem como objetivos o aperfeiçoamento da prática docente e das ações educativas no meio escolar. 


\section{autêntica}

\section{REFERÊNCIAS}

BETTI, Mauro. O que a semiótica inspira ao ensino da educação física. Discorpo, São Paulo, n. 3, p. 25-45, 1994.

BORGES, Cecília. O professor da educação básica de $5^{a}$ a $8^{a}$ série e seus saberes profissionais. Rio de Janeiro: PUC-RJ. Tese (Doutorado em Educação) - Faculdade de Educação, Pontifícia Universidade Católica do Rio de Janeiro, Rio de Janeiro, 2002.

BRACHT, V. Educação Física: conhecimento e especificidade. In: SOUZA, Eustáquia S.; VAGO, Tarcísio M. Trilhas e partilhas: Educação Física na cultura escolar e nas práticas sociais. Belo Horizonte: Cultura, 1997.

CASTELLANI FILHO, Lino et al. Metodologia do ensino de Educação Física. São Paulo: Cortez, 2009.

CELLARD, André. L'analyse documentaire. In: POUPART, Jean. et al. La recherche qualitative: enjeux épistémologiques et méthodologiques. Montreal, Paris, Casablanca: Gaëtan Morin, 1997.

CHERVEL, André. História das disciplinas escolares: reflexões sobre um campo de pesquisa. Educação e Realidade, Porto Alegre, n. 2, p.177-229, 1990.

DESBIENS, Jean-François. Comment comprendre lês savoirs à la base du controle et de la régulation de la supervision active em enseignement de l'educacion physique. In: BORGES, Cécilia; DESBIENS, Jean-François. Savoir, former et intervir dans une éducation physiqueen changement. Quebec: Editions du CRP, 2003.p. 50-72.

DEVALY, Michael. Savoirs scolaires et didatique dês discipline: une encyclopédie pour aujourd'hui. Paris: ESF Editeur, 1995.

DURAND, Marc. L'enseignement em milieu scolaire. Paris: PUF, 1996.

GAUTHIER, Clemont et al. Por uma teoria da Pedagogia. ljuí: Ed. da UNIJUí, 1998.

GAUTHIER, Clemont; DESBIENS, Jean-François; MARTINEAU, Stéphane. Mots de passe pour mieux enseigner. Quebec: Les Presses de L'Univsersité Laval, 2003.

HUBERMAN, Michael. O ciclo de vida profissional dos professores. In: NÓVOA, António (Org.). Vida de professores. Porto: Porto Editora, 1992. p. 31-61.

LESSARD, Claude; TARDIF, Maurice. Les identities enseignantes: analyse de facteurs de différenciation du corps enseignant québécois 1960-1990. Quebec: Editions duCRP, 2003.

MONTEIRO, Ana Maria Ferreira da Costa. Professores: entre saberes e práticas. Educação e Sociedade, Unicamp, ano XXII, n. 74, p. 121-142, abr. 2001.

PERRENOUD, Philipe. Lê role de la formation à l'enseignement dans la construcion des disciplines scolaires. Revue Educacion e Francophonie. v. XXVIII, n. 2, automne-hiver 2000. Disponível em: <http://www.acelf.ca/ revue>. Acesso em: 30 mar. 2003. 
SCHÖN, Donald. Educando o profissional reflexivo: um novo design para o ensino e a aprendizagem. Porto Alegre: Artes Médicas Sul, 2000.

SHULMAN, Lee. Those who understand: knowledge growth in teaching. Educacional Researcher, Washington, v. 15, n. 2, p. 4-14, feb. 1986.

TARDIF, Maurice; LESSARD, Claude. Le travail enseignant au quotidien. Experience, infractions humaines et dilemes professionnels. Paris: De Boeck, 1999.

TARDIF, Maurice. Saberes profissionais dos professores e conhecimentos universitários: elementos para uma epistemologia da prática profissional dos professores e suas consequências em relação à formação para o magistério. Revista Brasileira de Educação, n. 13, p. 5-24, jan./abr. 2000.

TARDIF, Maurice; LESSARD, Claude; LAHAYE, Luc. Os professores face ao saber: esboço de uma problemática do saber docente. Teoria \& Educação, n. 4, p. 215-233, 1991. 
